\title{
Capacity utilization of buyer-supplier relationships
}

\author{
Somayeh Mamizadeh-Chatghayeh ${ }^{1 *}$, Ghasem Tohidi $^{2}$, Shaghayegh Lankarani ${ }^{3}$ and Sanaz Mamizadeh-Chatghayeh ${ }^{4}$ \\ ${ }^{1}$ Young research club, Islamic Azad University, Central Tehran Branch, Tehran, Iran \\ ${ }^{2}$ Department Mathematics, Islamic Azad University of Central Tehran Branch, Tehran, Iran \\ ${ }^{3}$ Department Mathematics, Islamic Azad University of Central Tehran Branch, Tehran, Iran \\ ${ }^{4}$ Young research club, Islamic Azad University, Central Tehran Branch, Tehran, Iran
}

Somayeh_mamizadeh@yahoo.com

\begin{abstract}
The evaluation of performance in buyer-supplier relationships through the measurement of capacity utilization and profitability of information flows occurring between two or more members involved in a supply chain have been considered. Therefore, it introduces a modified slacks-based measure (MSBM) model for supply chain performance evaluation by regard intermediate production. The modified model shows the input excesses, output shortfalls and the efficiency or inefficiency supply chain simultaneously. Among the input resources for production, some are fixed and cannot be easily altered, while some are flexibly alterable. The paper concludes with an empirical illustration, involving data on 17 bank branches of China Construction Bank in Anhui province that is a typical buyer-supplier supply chain process.
\end{abstract}

Keywords: Buyer-Supplier relationships, Data envelopment analysis, Supply chain, Fixed and variable inputs, Capacity utilization

\section{Introduction}

In research environment of supply chain, many authors argue that gradual increments of information sharing produce a positive increase in the local and global performance of the supply chain (Willcocks \& Sauer, 2000). The key to operations strategy business performance and successful partnership for both sides is to work together to achieve a common goal. That is to secure business of supply chain which is profitable for both. If this business of supply chain, particularly buyersupplier is not mutually beneficial there is little point in pursuing it. Successful partnerships are supplier which needs to make a profit and the buyer must receive good value.

Despite the great interest in buyer-supplier partnership, however, the authors are not aware of any research in the field of supply chain management that measure relationships cooperative activities along with their associated outcomes, or relates to the outcomes the influence of contingent variables unique to each member.

Kleinsorge et al. (1992) considered the concept of the sup- ply chain i.a., customer-supplier relationships for a single carrier over several months are examined.

Data envelopment analysis (DEA) has gained great popularity in environmental performance measurement and has been applied to gauge the supply chain performance in several works such as, Narasimhan et al. (2001), use normalized data to address similar relationships in a DEA model. Many recent studies, however, fail to sufficiently address "quality" issues. Moreover, while most researchers concerned with relationship supply chain management have investigated the effectiveness of actions, the above studies seem to be the only ones that so far have established how efficient those actions are in terms of their resource use, or related that to the outcomes achieved with quality suppliers. This paper is on selecting the right method in the supply chain, to decide on capacity augmentation at the supplier to meet the demand requirements of a short lifecycle product at the retailer. A short lifecycle product is one that is sold for a short period of time.

This paper will address a DEA-based performance evaluation approach from the perspective of the overall buyer-supplier. In this model the supply chain are under the control of a unique decision maker, and the decision maker can determine the optimal capacity of intermediate products to maximize the overall performance score in DEA framework. In addition, by compared with other buyer-suppliers, the evaluated buyer-supplier can be identified as efficient or inefficient. The inefficiency perspective and corresponding improvement strategies for those inefficient buyer-suppliers can be given at the same time.

\section{Slacks based measures}

Tone (2001) introduced the so-called slacks-based measure (SBM) which is invariant to the units of measurement and is monotone increasing in each input and output slack. The SBM is derived from the solution of the fractional programming problem.

Fig. 1. Supply chain (buyer-supplier)

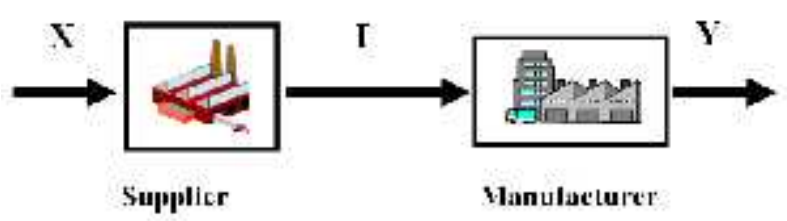

Popular article

CIndian Society for Education and Environment (iSee)
"Buyer-supplier relationship" http://www.indjst.org
S.M-Chatghayeh et al. Indian J.Sci.Technol. 
$(S B M) \min \rho=\frac{1-\left(\frac{1}{P}\right) \sum_{p=1}^{P} \frac{s_{p}^{-}}{x_{p d}}}{1+\left(\frac{1}{K}\right) \sum_{k=1}^{K} \frac{s_{k}^{+}}{i_{k d}}}$

s.t

$\sum_{j=1}^{N} \lambda_{j}^{s} x_{p j}+s_{p}^{-}=x_{p d}, p=1,2, \ldots, P$

$\sum_{j=1}^{N} \lambda_{j}^{s} i_{k j}-s_{k}^{+}=i_{k d}, k=1,2, \ldots, K$

$\lambda_{j}^{s} \geq 0, s_{p}^{-} \geq 0, s_{k}^{+} \geq 0, \forall j, p, k$.

Where $S_{p}^{-},(p=1,2, \ldots, P)$ and $S_{k}^{+},(k=1,2, \ldots, K)$ denote the input excesses and output shortfalls vectors, and $\lambda_{j}^{s},(j=1,2, \ldots, N)$ is nonnegative vector.

\section{Supply chain}

The great importance of power in the supply chain has shown that members they to assume a dominant position that gives them control over other members, namely, to provide the best high quality products and services at the least cost to demand more value, Cox (2001). In the context supply chain management (SCM) is related to the coordination of materials, products and information flows among suppliers, manufactures, distributors, retailers and customers (Simchi-Levi et al., 2000).

\section{Method}

In this section we introduce capacity utilization of buyer-supplier relationships using slacks-based measure of efficiency. Among input resources for production, some
Vol. 5 No. $9 \quad$ (Sep. 2012)

ISSN: 0974- 6846

are fixed and cannot be easily altered, e.g., fixed assets, capital, while some are flexibly alterable, e.g., expenditure or employee. Suppose that there are $\mathrm{N}$ twostage supply chains under evaluation, e.g., buyer-supplier as shown in Fig.1.

We denote the output vector of buyer-supplier $\mathrm{BS}_{\mathrm{j}}$, $(\mathrm{j}=1,2, \ldots, \mathrm{N})$ by $y_{j}=\left(y_{1 j}, \ldots, y_{Q j}\right) \in R^{Q}$ and its fixed and variable input vectors by $x_{j}^{F}=\left(x_{1 j}^{F}, \ldots, x_{j P_{1}}^{F}\right) \in R^{P_{1}}$ and $x_{j}^{V}=\left(x_{1 j}^{V}, \ldots, x_{j P_{2}}^{V}\right) \in R^{P_{2}}$, respectively. And also $\mathrm{K}$ outputs from each buyer $\mathrm{B}_{\mathrm{j}}, i_{k j}(k=1,2, \ldots, K)$. These $\mathrm{K}$ outputs become the inputs to the supplier $S_{j}$, and are referred to as intermediate products.

\section{Technical capacity utilization}

For an innovative product characterized by short product lifecycle and high demand uncertainty, investment in capacity buildup has to be done has to be done cautiously. Otherwise, either the product's market diffusion is impeded with unutilized capacity.

Therefore, given the set of observed buyer-supplier BSs $\left(x_{j}^{F}, x_{j}^{V}, i_{j}^{F}, i_{j}^{V}, y_{j}\right), j=1,2, \ldots, N$, we evaluate the efficiency of $B S_{d}=\left(x_{d}^{F}, x_{d}^{V}, i_{d}^{F}, i_{d}^{V}, y_{d}\right), d=1,2, \ldots, N$, using the output-oriented non-radial model slacks-based measure (SBM) of efficiency approach to solve the buyersupplier described in (1) as follows and we call this model the modified SBM (MSBM) model:

Table 1. Data of 17 bank branches

\begin{tabular}{|c|c|c|c|c|c|c|c|c|}
\hline NO & Bank Branch & Fixed Assets & Employee & Expenditure & Credit & Interbank Loan & Loan & Profit \\
\hline SC1 & Hefei & 1.0168 & 1.221 & 1.2215 & 166.976 & 8.3098 & 122.195 & 3.7569 \\
\hline SC2 & Bengbu & 0.5915 & 0.611 & 0.4758 & 50.1164 & 1.7634 & 19.4829 & 0.66 \\
\hline SC3 & Huainan & 0.7237 & 0.645 & 0.6061 & 48.2831 & 3.4098 & 34.412 & 0.7713 \\
\hline SC4 & Huaibei & 0.515 & 0.486 & 0.3763 & 35.0704 & 2.348 & 15.2804 & 0.3203 \\
\hline SC5 & Maanshan & 0.4775 & 0.526 & 0.3848 & 49.9174 & 5.4613 & 34.9897 & 0.843 \\
\hline SC6 & Tongling & 0.6125 & 0.407 & 0.3407 & 23.1052 & 1.2413 & 32.5778 & 0.4616 \\
\hline SC7 & Wuhu & 0.7911 & 0.708 & 0.4407 & 39.459 & 1.1485 & 30.2331 & 0.6732 \\
\hline SC8 & Anqing & 1.2363 & 0.713 & 0.5547 & 37.4954 & 4.0825 & 20.6013 & 0.4864 \\
\hline SC9 & Huangshan & 0.446 & 0.443 & 0.3419 & 20.9846 & 0.6897 & 8.6332 & 0.1288 \\
\hline SC10 & Fuyang & 1.2481 & 0.638 & 0.4574 & 45.0508 & 1.7237 & 9.2354 & 0.3019 \\
\hline SC11 & Suzhou & 0.705 & 0.575 & 0.4036 & 38.1625 & 2.2492 & 12.0171 & 0.3138 \\
\hline SC12 & Chuzhou & 0.6446 & 0.432 & 0.4012 & 30.1676 & 2.3354 & 13.813 & 0.3772 \\
\hline SC13 & Luan & 0.7239 & 0.51 & 0.3709 & 26.5391 & 1.3416 & 5.0961 & 0.1453 \\
\hline SC14 & Xuancheng & 0.5538 & 0.442 & 0.3555 & 22.2093 & 0.9886 & 13.6085 & 0.3614 \\
\hline SC15 & Chizhou & 0.3363 & 0.322 & 0.2334 & 16.1235 & 0.4889 & 5.9803 & 0.0928 \\
\hline SC16 & Chaohu & 0.6678 & 0.423 & 0.3471 & 22.1848 & 1.1767 & 9.2348 & 0.2002 \\
\hline SC17 & Bozhou & 0.3418 & 0.256 & 0.1594 & 13.4364 & 0.4064 & 2.5326 & 0.0057 \\
\hline
\end{tabular}

SC: Supply Chain (Yang et al., 2010)

S.M-Chatghayeh et al. Indian J.Sci.Technol. 


$$
\left(S B M_{\text {Buyer-Supplier }}\right) \max \rho=\left(1+\frac{1}{K} \sum_{k=1}^{K} \frac{s_{k}^{+}}{i_{k d}}+\frac{1}{Q} \sum_{q=1}^{Q} \frac{s_{q}^{+}}{y_{q d}}\right)
$$

s.t.

$\sum_{j=1}^{N} \lambda_{j} x_{p j}^{F} \leq x_{p d}^{F}, p \in P_{1}$

$\sum_{j=1}^{N} \lambda_{j} x_{p j}^{V} \leq x_{p d}^{V}, p \in P_{2}$

$\sum_{j=1}^{N} \lambda_{j} i_{k j}-s_{k}^{+}=i_{k d}, k=1,2, \ldots, K$

$\sum_{j=1}^{N} \mu_{j} i_{k j}^{F} \leq i_{k d}^{F}, k \in K_{1}$

$\sum_{j=1}^{N} \mu_{j} i_{k j}^{V} \leq i_{k d}^{V}, k \in K_{2}$

$\sum_{j=1}^{N} \mu_{j} y_{q j}-s_{q}^{+}=y_{q d}, q=1,2, \ldots, Q$

$\lambda_{j} \geq 0, \mu_{j} \geq 0$,

$s_{p}^{-} \geq 0, s_{k}^{+} \geq 0, s_{k}^{-} \geq 0, \forall j, p, k$.

This means $\rho^{*}>1$, that is the buyer-supplier $\mathrm{BS}_{d}$ can expand some outputs without worsening other outputs, using the current level of input resources.

We now relax model (1) by deleting the constraint $\sum_{j=1}^{N} \lambda_{j}^{s} x_{p j}^{V} \leq x_{p d}^{V}, p \in P_{2}, \sum_{j=1}^{N} \mu_{j}^{s} i_{k j}^{V} \leq i_{k d}^{V}, k \in K_{2}$, which bounds the variable input values below the observed values. This yields the following model.

$\left(S B M_{\text {Buyer-sup plier }}^{F}\right) \max \rho=\left(1+\frac{1}{K} \sum_{k=1}^{K} \frac{s_{k}^{+}}{i_{k d}}+\frac{1}{Q} \sum_{q=1}^{Q} \frac{s_{q}^{+}}{y_{q d}}\right)$

s.t.

$\sum_{j=1}^{N} \lambda_{j} x_{p j}^{F} \leq x_{p d}^{F}, p \in P_{1}$

$\sum_{j=1}^{N} \lambda_{j} i_{k j}-s_{k}^{+}=i_{k d}, k=1,2, \ldots, K$

$\sum_{j=1}^{N} \mu_{j} i_{k j}^{F} \leq i_{k d}^{F}, k \in K_{1}$

$\sum_{j=1}^{N} \mu_{j} y_{q j}-s_{q}^{+}=y_{q d}, q=1,2, \ldots, Q$

$\lambda_{j} \geq 0, \mu_{j} \geq 0$,

$s_{p}^{-} \geq 0, s_{k}^{+} \geq 0, s_{k}^{-} \geq 0, \forall j, p, k$.

Popular article

COIndian Society for Education and Environment (iSee)
Let us define a capacity utilization measure by

Buyer - Supplier $_{d}^{* \text { capacity.utilization }}=\frac{\rho^{*}}{\rho^{* F}}(\leq 1)$,

Where $\rho^{*}$ is exhibited in (1) and $\rho^{* F}$ is fixed in (2), then Buyer-Supplier ${ }_{d}^{* \text { capacity.utilization }}<1$, i.e., $\quad \rho^{* F}>\rho^{*}$ indicates that some of the bounding constraints are tight in model (1) and the average expansion rate can be increased by deleting these bounds for the variable inputs.

\section{Applications}

Table 1 exhibits data for 17 bank branches of China Construction Bank in Anhui province that is a typical buyer-supplier supply chain process. There are three inputs to the first stage such as Fixed Assets (FA), Employee (EM), Expenditure(EX), are consumed to generate outputs such as Credit(CR) and Credit (CR) and Interbank Loan (IL). In the second stage, the Credit (CR) and Interbank Loan (IL) are used to generate two outputs: Loan (LO) and Prot (PR). In this application, 17 branches of China Construction. The data are from Annual Report (2004) of China Construction Bank in Anhui Province. Table 1 exhibits a data set with two fixed input, one variable input, and one fixed intermediate product, one variable intermediate product and two outputs. Table 2. Technical capacity utilization

\begin{tabular}{|c|c|c|c|c|}
\hline NO & $\begin{array}{c}\text { Bank } \\
\text { Branch }\end{array}$ & $\rho^{*}$ & $\rho^{*}{ }^{*}$ & $\begin{array}{c}\text { Capacity } \\
\text { utilization }\end{array}$ \\
\hline SC1 & Hefei & 1.0000 & 1.0000 & 1.0000 \\
\hline SC2 & Bengbu & 3.2423 & 3.9492 & 0.8210 \\
\hline SC3 & Huainan & 2.2303 & 2.2303 & 1.0000 \\
\hline SC4 & Huaibei & 3.4438 & 3.4438 & 1.0000 \\
\hline SC5 & Maanshan & 1.5973 & 1.5973 & 1.0000 \\
\hline SC6 & Tongling & 2.5380 & 2.5380 & 1.0000 \\
\hline SC7 & Wuhu & 3.4474 & 4.5572 & 0.7565 \\
\hline SC8 & Anqing & 2.8769 & 2.9477 & 0.9760 \\
\hline SC9 & Huangshan & 5.8130 & 6.6772 & 0.8706 \\
\hline SC10 & Fuyang & 5.3482 & 6.5231 & 0.8199 \\
\hline SC11 & Suzhou & 4.4130 & 4.4957 & 0.9816 \\
\hline SC12 & Chuzhou & 2.9784 & 2.9784 & 1.0000 \\
\hline SC13 & Luan & 7.1139 & 7.3812 & 0.9638 \\
\hline SC14 & Xuancheng & 3.7997 & 4.0298 & 0.9429 \\
\hline SC15 & Chizhou & 5.8970 & 7.0030 & 0.8421 \\
\hline SC16 & Chaohu & 4.5455 & 4.5714 & 0.9943 \\
\hline SC17 & Bozhou & 25.0000 & 32.0000 & 0.7813 \\
\hline
\end{tabular}

Table 2 reports $\rho^{*}$ and $\rho^{*}$ scores of the two stages (buyer-supplier). Comparisons between columns 3 and 4 in Table 2, we can find out that SC1, SC3, SC4, SC5, SC6 and SC12 are efficient in the capacity utilization. Conclusions

In this paper we used the SBM model and proposed a modified SBM model to evaluate the capacity utilization of the buyer-supplier. Capacity utilization deals with the situation where some input values are fixed and cannot be easily altered while some are flexibly alterable. Thus, we divided inputs into fixed and variable inputs, and studied the effect on efficiency caused by the variable 
inputs according to whether relaxation of variable inputs improves the efficiency of buyer-supplier under evaluation. We analyzed aspects of capacity utilization in supply chain (buyer-supplier). Then, the discussion of return to scale can play main role to use of the best policy in the procedure of possibility to development \& evaluation in performance of supply chains and also, in its discussion of management.

\section{References}

1. Biresh K, Sahoo ab and Kaoru Tone (2009) Decomposing capacity utilization in data envelopment analysis: An application to banks in India. Eur. J. Operational Res.195, 575-594.

2. China Construction Bank (Anhui Branch). Annual report (2004) of China construction bank in Anhui province (in Chinese).

3. Cox A (2001) Understanding buyer and supplier power: A framework for procurement and supply competence. J. Supply Chain Managne., Spring. 37, pp: 8.

4. Eilon S (1985) A framework for profitability and productivity measures. Interfaces. 15, 31-40.

5. Johansen $L$ (1968) Production functions and the concept of capacity. Recherches Recentes sur la Function de Prodec., Collection Economy Mathematique Econometrie. 2, 46-72.

6. Kleinsorge IK, Schary PB and Tanner RD (1992) Data envelopment analysis for monitoring customersupplier relationships. J. Accoun. \& Public Policy. 11, 357-372.

7. Tone K (2001) A Slacks-based measure of efficiency in data envelopment analysis. Research reports, Graduate school of policy science, Saitama University and subsequently published. Eur. J. Operational Res. 130, 498-509.

8. Simchi-Levi D, Kaminsky P and Simchi-Levi E (2000) Designing and managing the supply chain: Concepts, strategies and case studies. NY: McGraw-Hill.

9. Willcocks $L$ and Sauer C (2000) Moving to ebusiness. Random house business book, London. Berndt, E. R. and C. J. Morrison (1981), Capacity utilization measures: underlying economic Theory and an alternative approach. Am. Econ. Rev. 71, 4852.

10. Yang Wu F, Ling D, Bi LG and Wu DD (2010) Supply chain DEA: production possibility set and performance evaluation model. Ann. Operation Res. DOI 10.1007/s10479-008-0511-2. 